\title{
Extreme prematurity in the UK and Denmark: population differences in viability
}

\author{
D Field, S Petersen, M Clarke, E S Draper
}

Arch Dis Child Fetal Neonatal Ed 2002;87:F172-F175

See end of article for authors' affiliations ......................

Correspondence to: Professor D Field, Department of Child Health, Robert Kilpatrick Clinical Sciences Building, University of Leicester, Leicester LE2 7LX, UK; david.field@uhl-tr.nhs.uk

Accepted 22 May 2002

\begin{abstract}
Background: Previous studies comparing different models of neonatal intensive care have generally not been population based. The objective of this study was to compare the perinatal services of two total populations.

Methods: Observational study based on two geographically defined populations: the whole of Demark (some centralisation of neonatal intensive care but most delivered locally by small perinatal centres -48 in total) and the Trent Health Region of the UK (no formal centralisation however deliveries almost all focussed on 16 major hospitals with $>90 \%$ of the intensive care provided by 13 hospitals). Information was recorded about the course of every liveborn infant $<28$ weeks gestation and or $<1000 \mathrm{~g}$ birth weight and $\geqslant 21$ weeks gestation in 1994 and 1995 .

Results: Despite having a smaller population the number of liveborn children meeting the study criteria was significantly higher in Trent (Demark 461 (3.3 per 1000 births, 95\% confidence interval (CI) 3.0 to 3.6); Trent 572 (4.9 per 1000 births, $95 \% \mathrm{Cl} 4.5$ to 5.3)). In Denmark $91.1 \%$ of these infants were admitted for intensive care and $85.5 \%$ in Trent. Despite significantly more Trent infants being exposed to antenatal steroids their outcome was worse (median Clinical Risk Index for Babies (CRIB) score $7 \vee 4$; proportion receiving ventilation $87.6 \% \vee 40.0 \%$; survival to discharge (uncorrected for disease severity) $42.3 \% \vee 35.0 \%$ ).

Conclusion: The population characteristics of Trent seemed to produce a higher prematurity rate compared to Denmark. These infants as a group appeared sicker and, despite more intensive care delivered by a more specialised service, outcomes were worse.
\end{abstract}

$\mathrm{T}$ hroughout the developed world, "quality of care" and "clinical effectiveness" are terms that are now in everyday use in clinical settings. Comparisons of apparently similar hospitals and regions are performed with the aim of ensuring that standards are comparable and, where this is not the case, any differences can be explored. ${ }^{1}$ Achieving a genuine "like for like" comparison of large patient populations is very difficult since most studies of this type are based on hospital populations and hence subject to referral bias and selective inclusion. Disease severity scoring systems have been developed in a number of specialties to permit standardisation of risk and hence attempt to deal with such bias. ${ }^{23}$

Neonatal intensive care (NIC) has been the subject of much attention in this regard probably because of its high cost per case. Assessments of the effectiveness of different sized units and international comparisons of alternative approaches to delivery of care have been performed. ${ }^{45}$ At an international level difficulties in identifying all the cases, especially all liveborn infants at the limit of viability, pose a particular challenge as the classification of such babies is known to vary. ${ }^{6}$ Because of their high mortality rate, differences in the approach to such infants may profoundly affect the apparent clinical effectiveness of a particular service since they may, depending on local practice, be either included or excluded from the study population. ${ }^{7}$

We wished to examine these issues more closely by comparing the NIC services of two European countries (United Kingdom and Denmark) known to have different approaches to NIC. The comparison was based on datasets containing particularly detailed information about the outcome of all livebirths at the limit of viability.

\section{METHODS}

Danish data were provided from the EFTOL study (a project initiated by the Danish Paediatric Society). All perinatal units participated in this prospective registration of extremely premature $(<28$ weeks) and or low birth weight $(<1000 \mathrm{~g})$ infants born in 1994 and 1995. Staff in each delivery unit in Denmark collected data for the study and returns were cross checked with official statistics. The overall perinatal mortality rate in 1994-95 was 7.75 per 1000 births with a range of 6.3 to 14.4 in the 16 health regions (counties) of Denmark.

Within Denmark, perinatal medicine is organised differently in the eastern part of the country (Zealand and the Eastern Islands) compared to the west (Jutland and Funen). In the east, complicated perinatal treatment is centralised to Copenhagen University Hospital (Rigshospitalet), and only one other neonatal unit in Copenhagen provides ventilator care for extremely preterm babies. Pregnant women with impending preterm delivery before 28 weeks gestation are transferred to Copenhagen University Hospital with transfer back scheduled at 31 weeks depending on the infant's condition. In the western part transfer to the two university hospitals is only indicated for severe malformations. Intensive care including ventilation is usually provided by the local hospital.

The number of delivery units in the eastern part of the country is 18; four of these have less than 1000 deliveries per year, 12 have 1000-3000 deliveries, and two have more than 3000 deliveries per year. In the western part of the country there are 30 delivery units; 15 of these have less than 1000 deliveries per year, 12 have 1000-3000 deliveries, and three have more than 3000 deliveries per year. Very few deliveries take place outside hospital and the general attendance at free prophylactic visits to antenatal clinics is high (above 99\%). $83 \%$ of deliveries in the east and $61 \%$ of deliveries in the west take place in a hospital with a paediatric service.

Representative data for the UK were obtained from the Trent Health Region. Trent has a population of approximately 4.6 million and there are about 60000 births per year. The 
Table 1 Population data for the two study groups derived from routine statistics

\begin{tabular}{|c|c|c|}
\hline & Trent $1994 \& 1995$ & Denmark 1994 \& 1995 \\
\hline Population & 4.6 million & 5.2 million \\
\hline Livebirths & 117309 & 140066 \\
\hline Stillbirth rate* per 1000 births $(95 \% \mathrm{CI})$ & 4.3 (3.9 to 4.7$)$ & 4.5 (4.2 to 4.9$)$ \\
\hline Perinatal mortality rate* per 1000 births $(95 \% \mathrm{Cl})$ & $8.1(7.6$ to 8.6$)$ & $7.7(7.3$ to 8.2$)$ \\
\hline Neonatal mortality rate per 1000 births $(95 \% \mathrm{CI})$ & $4.8(4.4$ to 5.2$)$ & 3.9 (3.6 to 4.3$)$ \\
\hline Infant mortality rate per 1000 births $(95 \% \mathrm{Cl})$ & 6.8 (6.4 to 7.3$)$ & 5.2 (4.8 to 5.6$)$ \\
\hline Total period fertility rate & 1.8 & 1.76 \\
\hline
\end{tabular}

Region is recognised as being demographically similar to England and Wales, with a mixture of urban and rural populations and similar mortality and morbidity measures. For example, the perinatal mortality rate in 1994-95 for England and Wales was 8.8 per 1000 total births and for the Trent Region was 9.3 per 1000 total births (range of 6.5 to 12.7 in the 12 Health Districts that made up Trent). Similarly, over the same period the proportion of babies less than $2500 \mathrm{~g}$ was $7.2 \%$ for England and Wales and $7.3 \%$ for Trent Region.

The Trent Neonatal Survey (TNS) is an on going study of neonatal intensive care activity in the Trent Health Region (UK). All of the perinatal services in Trent contribute to the TNS and units in adjacent regions also permit data collection on Trent infants. The present survey was established in February 1990. The database holds information relating to all infants of 32 weeks gestation or less, born to a Trent resident mother, and admitted to a neonatal unit since that time. Data for the Trent Neonatal Survey are collected by a group of five part time research nurses who visit each of the neonatal units on a regular basis and complete a standardise dataset about each baby. Information is obtained from the clinical records, discussions with staff and, where appropriate, personal observation. Data regarding immature infants who died outside a neonatal unit were obtained from the Confidential Enquiry into Stillbirths and Deaths in Infancy (CESDI). This is a similarly longstanding study that collates, from a variety of sources, data about all infants delivering after 20 weeks gestation either born dead or who die in the first year of life. Although the original Danish study had been based on a very specific group of babies ( $<28$ weeks and/or $<1000 \mathrm{~g}$ ) by using these two sources (TNS and CESDI) data equivalent to that available from Denmark was extracted.

The organisation of neonatal care in Trent differed quite markedly to that in Denmark. In Trent, at the time of the study, maternity care was centred on 16 perinatal units all with delivery and neonatal facilities. Access to regular antenatal assessment was freely available. The three smallest hospitals (with annual birth rates around 1000) offered no neonatal intensive care beyond stabilisation. However the remainder (annual birth rates 2000 to 6000) all aimed to offer neonatal intensive care to a percentage of their inborn babies. Although there were four recognised tertiary centres, their limited number of intensive care cots meant there was no strategy for these units to take in the bulk of high risk cases from the remainder of the region. Very few deliveries occurred at home or in private clinics. As a result almost all deliveries had immediate access to paediatric expertise.

\section{DEMOGRAPHIC DATA}

National statistics reveal that the two countries have many similarities with easy access to health care available to all. At the time of this study spending on "social programmes", as a percentage of gross domestic product was approximately $50 \%$ higher in Demark. ${ }^{8}$ The rate of teenage pregnancy was approximately four times higher in the UK. ${ }^{8}$

Health data relating to the two populations obtained from routine statistics are included in the results..$^{10}$

\section{RESULTS}

Centrally collected data for the two populations are shown in table 1 . The total period fertility rate for the two populations was very similar: $1.80 \mathrm{cf} 1.76$ per 1000 women aged 15 to 44 years. Routine data for stillbirth, perinatal, and neonatal mortality rates were adjusted for the Trent region (using CESDI data) to equate to the definitions used in Denmark: (stillbirths included babies born $\geqslant 28$ weeks gestation; perinatal mortality rate defined as stillbirths and deaths of livebirths in the first week; and neonatal mortality rate as: deaths of livebirths during the first 28 days). The neonatal and infant mortality rates for Denmark were significantly lower than the Trent rates while still birth rates were similar. Routine figures of this type are difficult to evaluate when it is impossible to ascertain if all livebirths have been consistently identified.

Table 2 is based on the two study populations. Both include data about all liveborn infants $<28$ weeks gestation and or $<1000$ g birth weight but $\geqslant 21$ weeks gestation. Two infants of 20 weeks gestation were admitted for neonatal intensive care in the Trent region but these have been excluded from the analysis. Given the immaturity of the study populations it was clear that a proportion of liveborn infants were not offered intensive care and instead remained on labour ward to be with their parents. On other occasions babies of this type were admitted to the neonatal unit for palliative care. It was not possible, with certainty, to separate those infants admitted to a neonatal unit for "terminal care" from those that died rapidly despite being offered active intensive support. Therefore both the Trent and Danish populations of babies were sub divided into two broad categories:

- Those born alive but never admitted to a neonatal unit;

- All those infants admitted to a neonatal intensive care unit.

Table 2 Population characteristics collected as part of the investigation

\begin{tabular}{|c|c|c|}
\hline & Trent $1994 \& 1995$ & Denmark $1994 \& 1995$ \\
\hline Liveborn infant $<28$ and $\geqslant 21$ weeks or $<1000 \mathrm{~g}$ & 572 & 461 \\
\hline Liveborn infant $<28$ and $\geqslant 21$ weeks or $<1000 \mathrm{~g}$ per 1000 livebirths $(95 \% \mathrm{Cl})$ & $4.88(4.50$ to 5.29$)$ & $3.31(3.02$ to 3.63$)$ \\
\hline Liveborn infant $<28$ and $\geqslant 21$ weeks or $<1000 \mathrm{~g}$ admitted to a neonatal unit & 489 & 420 \\
\hline Liveborn infant $<28$ and $\geqslant 21$ weeks or $<1000 \mathrm{~g}$ admitted to a neonatal unit per 1000 livebirths $(95 \% \mathrm{Cl})$ & $4.17(3.82$ to 4.56$)$ & 3.01 (2.74 to 3.31$)$ \\
\hline
\end{tabular}


Table 3 Clinical characteristics of infants admitted to NICUs with gestational age below 28 weeks or birth weight below 1000g in 1994-95

\begin{tabular}{llll}
\hline & Trent & Denmark & p Value \\
\hline Birthweight, g mean (SD) & $830.5(182.7)$ & $869.4(192.7)$ & $0.0019^{*}$ \\
Gestational age, weeks mean (SD) & $26.4(2.1)$ & $26.6(2.0)$ & $0.2386^{*}$ \\
CRIB score (median, IQ range) & $7(4$ to 11$)$ & $4(1$ to 7$)$ & $<0.0001 \dagger$ \\
Length of stay, days (surviving infants) (median, IQ range) & $81(60$ to 105) & $78(67$ to 92$)$ & $0.5624 \dagger$ \\
Total & 489 & 420 & \\
& & & \\
\hline & $n(\%)$ & $\mathrm{n}(\%)$ & $\mathrm{p}$ Value for $\chi^{2}$ test \\
\hline Male & $273(55.8)$ & $221(52.6)$ & 0.3331 \\
Multiple & $132(26.4)$ & $145(34.5)$ & 0.0077 \\
Antenatal Steroids & $334(68.3)$ & $234(55.7)$ & 0.0020 \\
Caesarean section & $229(46.8)$ & $242(57.6)$ & 0.0012 \\
Transport & $220(45.0)$ & $171(40.7)$ & 0.1943 \\
Surfactant & $303(62.0)$ & $172(41.0)$ & $<0.0001$ \\
Ventilator treatment & $430(87.9)$ & $168(40.0)$ & $<0.0001$ \\
CPAP treatment & $112(22.9)$ & $348(82.8)$ & $<0.0001$ \\
Oxygen at day 28 (of infants alive on day 28) & $208(67.8)$ & $148(51.9)$ & $<0.0001$ \\
Neonatal mortality (<28 days) & $182(37.2)$ & $135(32.1)$ & 0.1094 \\
Total mortality & $207(42.3)$ & $147(35.0)$ & 0.0238 \\
\hline *t test; †Wilcoxon test. & & & \\
CRIB, Clinical Risk Index for Babies; CPAP, continuous positive airway pressure. & \\
\hline
\end{tabular}

The rate of livebirth at this gestation was significantly higher in Trent (Demark 461 (3.3 per 1000 births, 95\% confidence interval (CI) 3.0 to 3.6); Trent 572 (4.9 per 1000 births, $95 \%$ CI 4.5 to 5.3)). Of these infants $91.1 \%$ were admitted for intensive care in Denmark and $85.5 \%$ in Trent. Twice as many low gestation infants in Trent were born alive but not offered intensive care $(83 v 41)$.

Although data about babies born dead at this gestation were available for Trent, equivalent data were not collected in Demark.

Comparing the two groups admitted to a neonatal unit revealed some striking differences (table 3 ). The Danish babies were more likely to be delivered by caesarean section. However the Trent infants, despite being more likely to be exposed to antenatal steroids, had evidence of higher levels of disease severity (disease severity was assessed using the Clinical Risk Index for Babies (CRIB) scores ${ }^{2}$ ) and received more aggressive intensive care (rates of ventilation were double). Crude survival was significantly better in the Danish group.

Survival in both settings, corrected for disease severity using CRIB, fell within the range predicted by the adjustment model (Trent actual deaths 176 predicted 180.0 (95\% CI 163.7 to 196.2); Denmark actual deaths 91 predicted 87.0 (95\% CI 73.5 to 100.6)). CRIB data was missing for 64 infants from Trent of whom 31 (48.4\%) died and 97 infants from Denmark of whom $56(57.7 \%)$ died. It seems likely that, in both

Table 4 Neonatal fatality rates (NIC admissions) by maternal age for Trent and Denmark

\begin{tabular}{|c|c|c|c|c|}
\hline \multirow[b]{3}{*}{ Mothers' age } & \multicolumn{4}{|c|}{ Neonatal case fatality } \\
\hline & \multicolumn{2}{|c|}{ Trent } & \multicolumn{2}{|c|}{ Denmark } \\
\hline & $\mathrm{n}$ & $\begin{array}{l}\text { rate/1000 } \\
\text { births }\end{array}$ & $\mathrm{n}$ & $\begin{array}{l}\text { rate/1000 } \\
\text { births }\end{array}$ \\
\hline$<20$ years & 16 & 285.7 & 6 & 352.9 \\
\hline $20-24$ years & 50 & 431.0 & 26 & 456.7 \\
\hline $25-29$ years & 54 & 357.6 & 44 & 363.6 \\
\hline $30-34$ years & 45 & 409.1 & 43 & 330.8 \\
\hline $35-39$ years & 13 & 276.6 & 14 & 205.9 \\
\hline $40+$ years & 4 & 666.7 & 2 & 222.2 \\
\hline Total & 182 & 374.5 & 135 & 321.4 \\
\hline
\end{tabular}

countries, many of the infants who died without CRIB data being collected were admitted for palliative care.

In order to investigate whether there was a greater degree of selection of cases offered intensive care in Denmark we repeated the comparison set out in table 3 using two subsets of the whole population:

- Those 27 and 28 weeks gestation (the latter only being included in the study population because they had a birth weight $<1000 \mathrm{~g}$ );

- Those with birth weights between $750 \mathrm{~g}$ and $999 \mathrm{~g}$.

We felt livebirths in these categories were least likely, in either setting, to have been not offered intensive care or been inappropriately considered as born dead. The results showed exactly the same pattern of difference as set out in table 3.

There was a significant difference in the maternal age of babies admitted for neonatal care (median maternal age Trent 27 (Q1-Q3 23-31); Denmark 30 (Q1-Q3 26-33)); Wilcoxon two sample test $\mathrm{p}<0.01$. Table 4 demonstrates neonatal fatality rates associated with various bands of maternal age. A trend towards a lower rate was observed amongst Danish women $\geqslant 30$ years but this group was not significantly different to the rate for younger women in Denmark or comparable groups in Trent. However numbers are small and the confidence interval very wide. Neonatal case fatality Trent women <30 372 (95\% CI 311 to 444), $\geqslant 30380$ (95\% CI 297 to 488); Danish women <30 389 (95\% CI 311 to 488 ), $\geqslant 30285$ (95\% CI 221 to 368 ).

\section{DISCUSSION}

This study has identified marked differences in not only the rate of delivery at $\leqslant 28$ weeks gestation and or $\leqslant 1000 \mathrm{~g}$ birth weight in these two populations but also in the behaviour of the babies. There appear to be three potential explanations for these findings.

It is possible that the observed differences are artefactual since this is a post hoc comparison of two datasets collected for quite different reasons. In particular comparative data about infants $<28$ weeks gestation and or $<1000 \mathrm{~g}$ birth weight born dead were not available. Therefore it is possible that large numbers of immature infants were wrongly classified in Denmark (but not in the UK). ${ }^{7}$ However it is important to note that both studies prospectively identified the same patient groups as well as employing detailed cross checks to 
prevent cases being missed. In addition the clinical course of the babies that were included was strikingly different, even when considering subsets with only the largest and most mature infants.

A second explanation is that the more centralised, more specialist based, UK perinatal service resulted in higher rates of prematurity and sicker babies. This seems implausible given that most premature infants are the result of spontaneous rupture of the membranes or spontaneous preterm labour. In addition the organisation of perinatal care in the UK meant that every one of these mothers and babies had immediate access to consultant obstetric support and neonatal intensive care. It seems unlikely, therefore, that the poorer outcomes were the result of systematically worse care from a more specialised and more centralised service than that operating in Denmark as a whole.

Alternatively these findings may indeed be an accurate reflection of innate reproductive health in the two countries and this is our view. Whilst we accept that some misclassification may have occurred it seems unlikely this involved more than a small number of infants. It has long been accepted that "adverse social circumstances" result in higher rates of prematurity, ${ }^{11}$ however, there has been no data to suggest that this type of social disadvantage can influence the baby's chances of survival in addition to the risks attaching to prematurity per se. While the UK cannot be considered a poor country, and in many ways is very similar to Denmark, there are important differences-for example, the high rates of teenage pregnancy and lower social spending per head of population. $^{8-10}$

We are not in a position to hypothesise about a particular biological mechanism that might have adverse effects on the fetus. However there is increasing evidence that an adverse in utero environment can affect the health and development of the fetus and baby. The evidence is particularly strong in relation to in utero exposure to infection. ${ }^{12}$ There is similarly support for the concept that intra uterine development governs many aspects of health in later life. ${ }^{13}$ It is therefore plausible, biologically, that adverse social circumstances may have wider effects than simply increasing the risk of premature delivery.

We do not believe these findings are a product of the organisation of perinatal care in the two countries. Therefore the results lead to two different conclusions depending on which of the remaining explanations is correct. (1) If special studies based in highly developed countries cannot reliably identify all liveborn children then routine figures for perinatal mortality and comparisons, even within individual countries, are probably worthless. (2) Alternatively if inequalities in parental living standards can lead to significant differences in the health of babies born at any given gestation we need to give great thought to potential mechanisms and also re-think how we deal with our more deprived populations. This would include not only how we deliver services but also how we judge success in comparison to more affluent groups in the same or other countries.

\section{ACKNOWLEDGEMENTS}

We wish to thank those involved in the original EFTOL study and the Trent perinatal teams for their collaboration with the Trent Neonatal Survey. The Trent Neonatal survey is funded by the Trent Health Authorities. ESD is funded by Leicestershire Health.

\section{Conflicts of interest \\ None.}

\section{Contributors}

DF and SP developed the original study concept. ESD and SP carried out the analysis, MC and DF were responsible for the evaluation of the data. All of the authors contributed to the final version of the paper. $\mathrm{DF}$ and SP act as guarantors for the paper.

\section{Authors' affiliations}

D Field, Dept of Child Health, University of Leicester, UK

S Petersen, Copenhagen University Hospital, Rigshospitalet, Dept of Neonatology, Denmark

M Clarke, E S Draper, Dept of Epidemiology and Public Health, University of Leicester Medical School, 22-28 Princess Road West, Leicester, UK

\section{REFERENCES}

1 Pearson G, Shann F, Barry P, et al. Should paediatric intensive care be centralised? Trent versus Victoria. Lancet 1997:349:1213-17.

2 International Neonatal Network. The CRIB (clinical risk index for babies) score: a tool for assessing initial neonatal risk of mortality and comparing performance of neonatal intensive care units. Lancet 1993;342:193-8.

3 Shann F, Pearson G, Slater A, et al. Paediatric index of mortality (PIM): a mortality prediction model for children in intensive care. Intensive Care Med 1997;23:201-7.

4 International Neonatal Network, Scottish Neonatal Consultants, Nurses Collaborative Study Group. Risk adjusted and population based studies of the outcome for high risk infants in Scotland and Australia. Arch Dis Child Fetal Neonatal Ed 2000;82:F1 18-23.

5 Field D, Draper ES. Survival and place of delivery following preterm birth: 1994-96. Arch Dis Child Fetal Neonatal Ed 1999;80:F1 11-17.

6 Evans DJ, Levene MI. Evidence of selection bias in preterm survival studies: a systematic review. Arch Dis Child Fetal Neonatal Ed 2001;84:F79-84.

7 Fenton AC, Field DJ. Attitudes to viability of preterm infants and their effect on figures for perinatal mortality. BM 1990;300:434-6.

8 Highlights on Health in Denmark. Epidemiology, Statistics and Health Highlights on Health in Denmark. Epidemiology, Statistics and Health
Information unit WHO Regional Office for Europe. http://www.who.dk/ country/dan01.pdf

9 Statistics Denmark. www2.dst.dk/internet/startuk.htm

10 National statistics. The official UK statistics site: www.statistics.gov.uk

11 MacFarlane A, Mugford M. Characteristics of parents and the circumstances in which they live. In: MacFarlane A, Mugford M, eds. Circumstances in which they live. In: MacFarlane A, Mugford M, eds.
Birth counts: statistics of pregnancy and childbirth. London: HMSO, 1984.

12 Goldenberg RL, Hauth JC, Andrews WW. Intrauterine infection and preterm labour. N Engl J Med 2000;342:1500 -7.

13 Barker DJP, Osmond C, Winter PD, et al. Weight in infancy and death from ischaemic heart disease. Lancet 1989;2:577-80. 